\title{
Spectrophotometric Determination of Mercury Ions with the New Reagent N-Methylanabazin-A-Azo-1,8-Aminonaphthol-4,6-Disulfonic Acid
}

\author{
Ashirov Mansur Allanazarovich ${ }^{1}$, Yangibaev Azim Erkhanovich ${ }^{2}$, \\ Khalilova Lola Mekhriddinovna ${ }^{3}$, SmanovaZulaykho Asanaliyevna ${ }^{4}$ \\ ${ }^{I}$ Research fellow, KhorezmMa'mun academy, Khiva, Uzbekistan \\ ${ }^{2}$ Candidate of Chemistry, National University of Uzbekistan, Tashkent, Uzbekistan \\ ${ }^{3}$ Lecturer, Department of Methods of Teaching Chemistry, Navoi State Pedagogical Institute \\ ${ }^{4}$ Professor of the Chemistry faculty of the National University of Uzbekistan, Tashkent, Uzbekistan \\ ${ }^{1}$ mansur.ashirov.86@mail.ru \\ 2 yangibayev69@mail.ru \\ ${ }^{4}$ smanova.chem@mail.ru
}

\begin{abstract}
The article provides information on the proposed sorption-spectroscopic methods for the quantitative determination of mercury (II) ions with a new synthesized reagent. In particular, according to the results of the assessment of the methodology carried out by such parameters as the limit of quantitative determination, reproducibility, lower limit of the determined contents, the results of immobilization of organic reagents on fibrous sorbents CMA-1, their analysis of lines by IR spectra, accuracy and correctness, it was found that the developed method is not inferior to other known methods for determining according to the specified requirements.
\end{abstract}

Key words: Toxic metals, lead, heavy metals, organic reagent, spectrophotometry.

\section{INTRODUCTION}

The need to control the chemical composition of the raw materials and products used for the content of toxic metals is indicated in the recent decisions of the Government of the Republic of Uzbekistan aimed at intensifying the national economy, improving product quality and environmental protection measures [1].

The determination of foreign substances in water and food products resulting from environmental pollution becomes more and more relevant every year, in connection with the abovementioned facts.

In this regard, the actual issue is the determination of toxic metals, including mercury, lead, cadmium and other heavy metals due to the established toxic effects of these elements on the human body.

In this regard, in order to obtain reliable information on the content of mercury, lead and cadmium, it is necessary to conduct constant analytical monitoring of the content of toxic metals in environmental objects and food products.

\section{MATERIALS AND METHODS}

In recent years, a number of publications [2-7] are devoted to the problems of environmental pollution and environmental monitoring. In [2-7], various aspects that are related to the influx of heavy and toxic metals into the environment, as well as the effects of these substances on the human body, were studied. Heavy metals (HM) take the second place in terms of hazard, yielding to pesticides and they are significantly ahead of such widely known pollutants as carbon dioxide and sulfur, in the forecast, they may become more dangerous than nuclear waste and solid waste [8]. Heavy metal pollution is associated with their widespread use in industrial production, coupled with poor cleaning systems, as a result of which heavy metals enter the environment, including the aquatic environment, polluting and poisoning it. The main sources of anthropogenic emissions of HM into the environment are various manufacturing enterprises, the burning of oil and various wastes, the production of glass, fertilizers, cement, etc. The most powerful halos of HM arise around enterprises of ferrous and especially non-ferrous metallurgy as a result of atmospheric emissions. The effect of pollutants extends to tens of kilometers from the source of elements in the atmosphere. So, metals in an amount of 10 to $30 \%$ of the total atmospheric emissions are distributed over a distance of $10 \mathrm{~km}$ or more from an industrial enterprise. At the same time, combined pollution of plants is observed, consisting of direct sedimentation of aerosols and dust on the surface of leaves and root assimilation of HM accumulated in the soil for a long time when pollution comes from the atmosphere [9-11]. The largest amount of air polluting substances is emitted from automobile exhaust. The most dangerous pollutants include mercury, lead and cadmium.

Modern requirements for the analysis of environmental objects and food products include the development of new highly sensitive and rapid methods for the determination of toxic metals. The 
multicomponent nature of the objects of analysis, low concentrations of metallic pollutants to solve such problems, necessitate the use of combined methods of analysis, including the stage of concentration. One of the promising methods for the determination of metals in nature-complex objects is spectrophotometric analysis methods [13]. Many photometric and electrochemical methods have been proposed [12, 14-16] for determining mercury, but the disadvantage of these methods is their low sensitivity and selectivity, therefore the development of simple highly sensitive analytical methods for controlling mercury content in various objects is relevant, since mercury is one of the most toxic metals and hazardous environmental pollutants.

The aim of the work is spectrophotometric determination of mercury using the new organic reagent $\mathrm{N}$-methylanabazin- $\alpha$-azo-1,8-aminonaphthol-4,6-disulfo nic acid (MAA), synthesized at the Department of Analytical Chemistry of the National University of Uzbekistan.

Solutions, reagents, sorbents. An initial $0.01 \mathrm{M}$ mercury solution was prepared by dissolving an exact portion of $0.3300 \mathrm{~g}$ of $\mathrm{Hg}\left(\mathrm{NO}_{3}\right)_{2}$ in $100 \mathrm{ml}$ of $0,1 \mathrm{M}$ $\mathrm{HNO}_{3}$. A working solution with a content of $5 \mu \mathrm{g} / \mathrm{ml} \mathrm{Hg}$ (II) was prepared by diluting the initial solution with 0.01 $\mathrm{M} \mathrm{HNO}_{3}$. The mercury concentration was determined titrimetrically according to the procedure [13].

A solution of the organic reagent, $\mathrm{N}$-methylanabazin- $\alpha$-azo-1,8-aminonaphthol-4,6-disulfo nic acid (MAA), was prepared by dissolving its necessary weight of the drug in bidistilled water, the concentration of which was $\mathrm{C}=1 \cdot 10-3 \mathrm{~mol} / 1$.

Metal salts and other reagents had the qualification of "chemically pure" or "pure for analysis" and were not subjected to additional cleaning. Their concentrated solutions were prepared by precise dilution of the starting bidistillates before starting the experiment.

Solutions of buffer mixtures and metals were prepared from the corresponding salts and acids of the qualification of chemically pure and special pure [14]. Bidistilled water was used for the experiment. The distiller Heal Force CR-RO30 was used. Chemical analysis for the content of various salts was not established. The conductivity of bidistilled water is 0.475 $\mathrm{mSm} / \mathrm{m}$.

The optical density of the solutions was measured on KFK-2, the $\mathrm{pH}$ of the solutions was measured on an I-130 ion meter and a $\mathrm{pH} / \mathrm{mv} /$ temp METER P25 ECOMET pH meter (Korea). Quantitative determination of mercury was measured on a SPEKTROCIROS VISION instrument, which is an automatic optical emission spectrometer with a source excitations in the form of inductively coupled plasma with a detection system.

\section{Synthesis of Anabazine Dye (MAA Acid)}

0.1 M diazotized N-amino- $\alpha$-methylanabazine dissolved in $25 \mathrm{ml}$ of absolute ethanol, $0.1 \mathrm{M}$ sodium salt of 1,8-aminonaphthol-4,6-disulfonic acid dissolved in $110 \mathrm{ml}$ of DMF is added. The reaction mass is thoroughly mixed and carbon dioxide is passed through it. After 5-6 days, the mother liquor is filtered off from the precipitate and the main product is precipitated by introducing a 5 -fold excess of chloroform. The precipitated flocculent of the desired azo dye is filtered off using a Buchner funnel. To clean it, the dry product of azo dye is passed through a column filled with alumina. Distilled water was used as eluent. The reagent yield was $56.8 \%$ of theoretically expected. In its pure form, MAA acid is a dark brown powder, readily soluble in water, DMF and pyridine, but insoluble in benzene, acetone, ether and chloroform, poorly soluble in ethanol.

Using thin-layer chromatography in the ethanol-acetic acid-water system (1: 0.5: 1), the individuality of the isolated reagent $(\mathrm{Rf}=0.75)$ was established.

Method of determination. An aliquot of the test solution containing a certain amount of metal in the linearity range of the calibration graph is added to a $25.00 \mathrm{ml}$ volumetric flask, a solution of MAA acid reagent, $5 \mathrm{ml}$ of universal buffer solution with an optimal $\mathrm{pH}$ of 6.5 are added. The solution is diluted with water to $25 \mathrm{ml}$, then the optical density of the solutions is measured at the maximum light absorption of the complex compound of the ion being determined relative to the solution of the control experiment prepared under the same conditions. The absorption spectra of the studied complex were recorded relative to the reagent solution. The complex has a high optical density in the region of $670 \mathrm{~nm}$.

\section{RESULTS AND DISCUSSION}

In the synthesis of the reagent, an increase in the molecular weight of the reagent, which increases the sensitivity of analytical determination methods and the affinity for the used organic reagents, is no less important. Due to the purposeful change in the structure of the azo dye, not only due to the introduction of additional analytical groups, but also due to their immobilization, a significant change in the properties of the complexes is possible, and thus theoretically and practically control the selection of specific analytical reagents.

The optimal conditions for the complexation of MAA with mercury ions were found as a result of the selection of the reagent concentration and the retention time of the carrier disk in the reagent solution. The interaction of mercury (II) with MAA was studied depending on the time and volume of the solution, the medium, the data are given in table 1.

Table 1: Optimal Conditions for the complexation of mercury with MAA

\begin{tabular}{|c|c|c|c|c|c|c|}
\hline $\begin{array}{c}\text { Tim } \\
\text { e, } \\
\text { hour }\end{array}$ & $\begin{array}{c}\text { Temperatu } \\
\text { re 0, C }\end{array}$ & $\begin{array}{c}1, \\
\mathrm{c} \\
\mathrm{m}\end{array}$ & $\begin{array}{c}\text { Volum } \\
\text { e of } \\
\text { solutio } \\
\mathrm{n} \mathrm{ml},\end{array}$ & $\begin{array}{c}\mathrm{C} \\
\text { reagen } \\
\mathrm{t}, \\
\%\end{array}$ & $\begin{array}{c}\mathrm{p} \\
\mathrm{H}\end{array}$ & Buffer \\
\hline 48 & $200 \mathrm{C}$ & $\begin{array}{c}1, \\
0\end{array}$ & 1,0 & 0,1 & $\begin{array}{c}6, \\
5\end{array}$ & $\begin{array}{c}\text { Univers } \\
\text { al }\end{array}$ \\
\hline
\end{tabular}

Spectroscopic methods established the nature of MAA and its complexes with mercury ions. Based on the 
studies, a mechanism for the complexation of the MAA reagent with mercury ions is proposed. The interaction proceeds according to the functionally active groups of the reagent, and the existing analytically active group takes part in the immobilization.

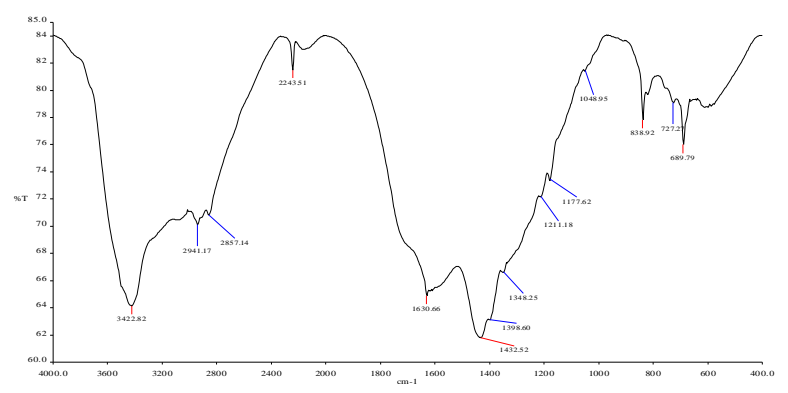

Figure 1: IR Spectrum of Fiber CMA-1

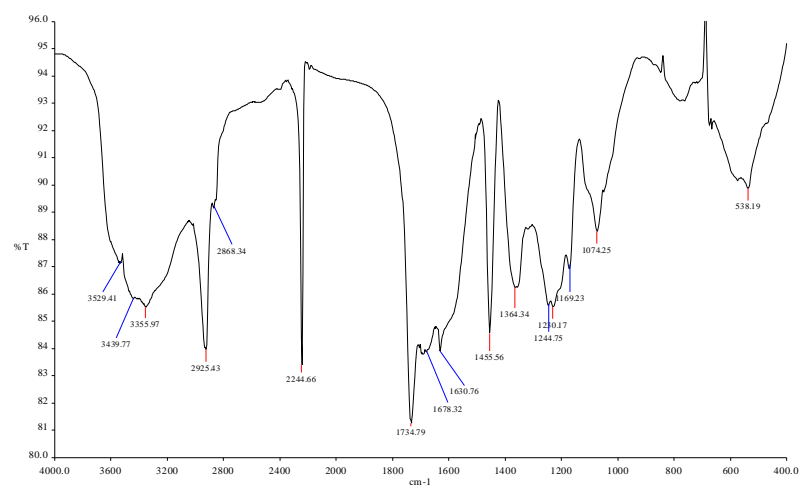

Figure 2: IR Spectrum of a Fiber with the Hg-R Complex Immobilized on it

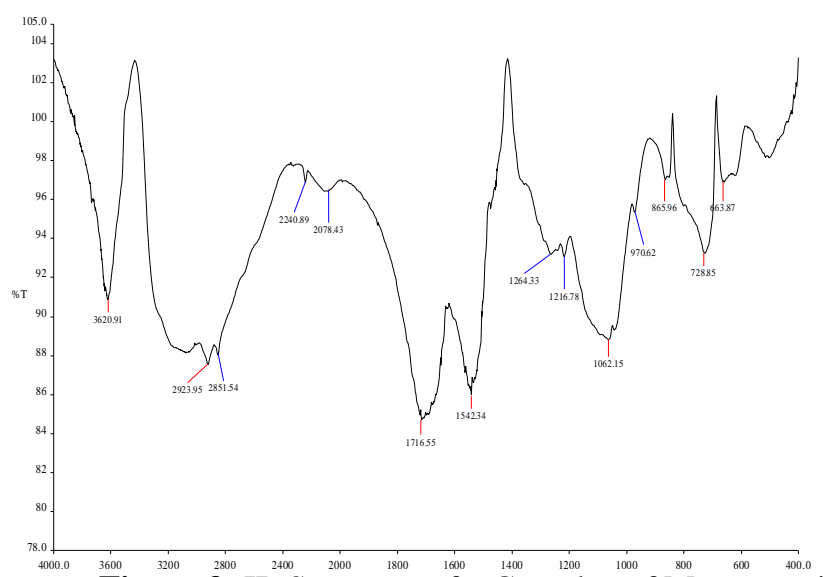

Figure 3: IR Spectrum of a Complex of Mercury with MAA Immobilized on SMA-1

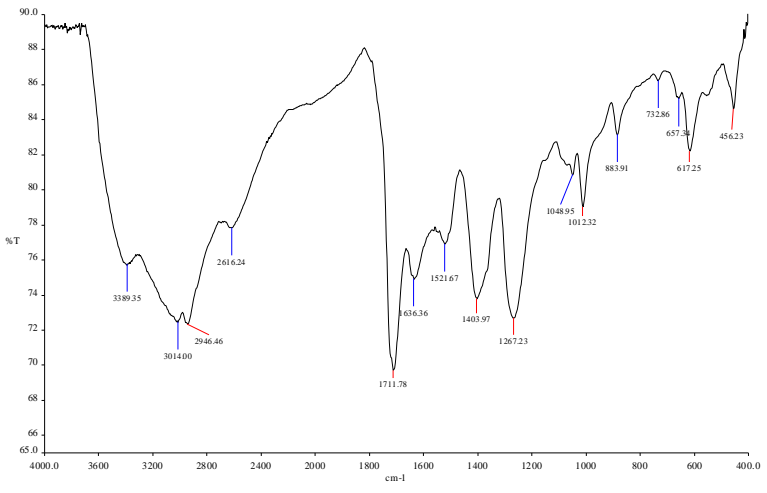

Figure 4: MAA

(N-Methylanabazin- $\alpha$-Azo-1,8-Aminonaphthol-4,8 Disulfonic Acid)

An essential feature of azo dyes is the presence in the molecule of $\mathrm{N}$-methylpiperidine nucleus. Since the tertiary $\mathrm{N}$-methyl group is strongly basic and the nitrogen of aliphatic amines is not capable of forming a $\pi$-bond with mercury ions, and therefore one should not expect the formation of a sufficiently strong coordination bond for this nitrogen azo dye. Due to the complexity of the dye molecule, a very important role should be attributed to steric properties during the formation of complexes. In this regard, the $\mathrm{N}$-methylpiperidine system can play a two-fold role: create a hindrance to the interaction of the pyridine nucleus in the third coordinate, six or more coordinating ions, thereby creating conditions for the second or third dye molecule to enter the coordination sphere, or vice versa, this group can prevent the second azo dye molecules into the coordination sphere. Apparently, this effect should be manifested for ions forming 3, 4, and 5 coordination bonds.

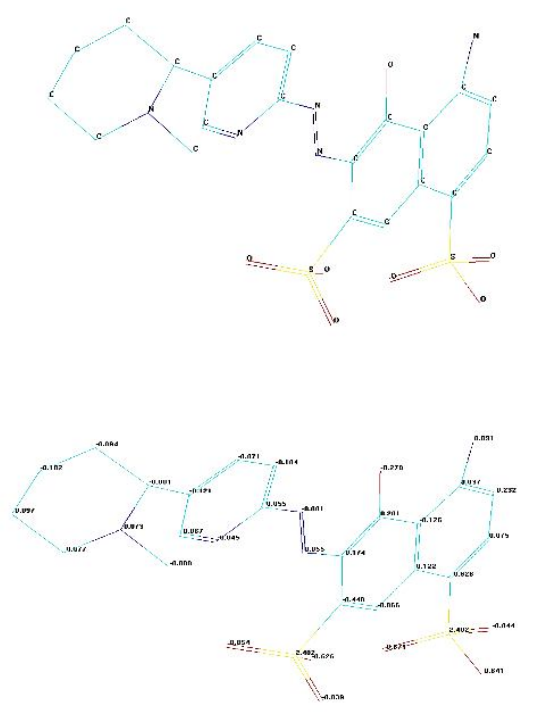

Figure 5: The Structural Formula of

N-Methylanabazine- $\alpha$-Azo-1,8-Aminonaphthol-4,8

Disulfonic Acid Calculated According to the Program PM 3 
In the IR spectra of the reagent there are a number of characteristic bands corresponding to its functionally analytical groups. So, in the spectrum there are bands with values of 2800-3500, 1632, 1500-1550 and $1200 \mathrm{~cm}-1$ corresponding to the $\mathrm{OH}$ group (located at the benzene ring and included in the carboxyl group), $-\mathrm{COOH},-\mathrm{CH}=$ $\mathrm{CH}-$ and $-\mathrm{N}=\mathrm{N}$-groups. During the complexation of MAA with mercury ions, a significant change occurs in the IR spectra of the complex in accordance with the composition and structure of the deposited substance. In the IR spectrum of the complex, a shift of bands at 2925, 1734 , and $1455 \mathrm{~cm}-1$, related to $-\mathrm{C}_{6} \mathrm{H}_{5} \mathrm{~N},-\mathrm{OH}$, and $-\mathrm{N}=\mathrm{N}-$ groups, is detected. Here, apparently, the main interaction is on the azo-hydroxy and amino groups of the reagent.

Table 2: Metrological Characteristics of the Complex Hg (II) with the Reagent MAA

\begin{tabular}{|c|c|c|}
\hline № & Characterictics & Values \\
\hline $\mathbf{1}$ & $\begin{array}{c}\text { Sendel sensitivity, } \\
\mathrm{mcg} / \mathrm{cm}^{2}\end{array}$ & 0,0053 \\
\hline $\mathbf{2}$ & $\begin{array}{c}\text { Molar coefficient } \\
\text { of light absorption }\end{array}$ & $5,4 \cdot 10^{4}$ \\
\hline $\mathbf{3}$ & $\lambda \max (\mathrm{HR}), \mathrm{nm}$ & 540 \\
\hline $\mathbf{4}$ & $\lambda \max (\mathrm{MeR}), \mathrm{nm}$ & 670 \\
\hline $\mathbf{5}$ & Content Me: $\mathrm{R}$ & $1: 2$ \\
\hline
\end{tabular}

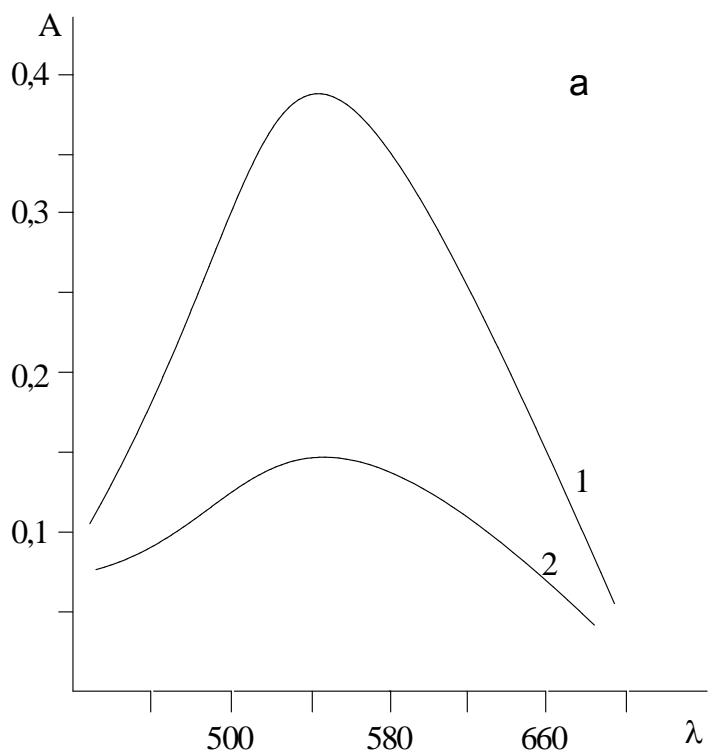

Figure 6: The Absorption Spectrum of the Reagent Before (1) and After (2) Immobilization on the Fiber CMA-1

Solutions of complex compounds of the reagent with mercury ions obey the Bouguer-Lambert-Beer law. A proportional relationship between the optical density and the number of metal ions is observed over a fairly wide concentration range (Fig. 6).
The calibration schedule for the determination of mercury was constructed as follows: A variable amount (from 2.00 to $15.00 \mu \mathrm{g}$ ) of the metal was measured into volumetric flasks, $5.0 \mathrm{ml}$ of universal buffer solution and bidistilled water were mixed to the mark and passed through a carrier immobilized with MAA reagent for a certain time. Based on the results obtained, a calibration graph is constructed, the calculation of the mathematical statistics of which showed that the deviation of the free term of the equation from zero is random, and the straight line passes through the origin $\mathrm{QMe}=1.58 \mathrm{~A}$, where $\mathrm{A}$ is the optical density, QMe is the found amount of mercury in $\mu \mathrm{g}$.

To assess the correctness and reproducibility of the sorption-photometric method for the determination of mercury by the MAA reagent, various quantities of the element were determined under optimal conditions in triplicate. The results of the experiment showed that the relative standard deviation $(\mathrm{Sr})$ when determining 0.20-5.00 $\mu \mathrm{g}$ of mercury does not exceed 0.052.

The effect of various foreign ions on the sorption-photometric determination of mercury by the MAA reagent was studied by a similar method, except that the number of foreign ions was added before the introduction of the azo dye solution. The experimental data are presented as the selectivity factor

$$
\left(\mathrm{F}=\frac{C_{M e}}{C_{N i}}\right)
$$

maximum permissible mass excess. The maximum determination error in all cases does not exceed $\pm 2 \%$. Judging by the values of the molar repayment coefficients (Table 2), the reaction of mercury with the MAA reagent is highly sensitive.

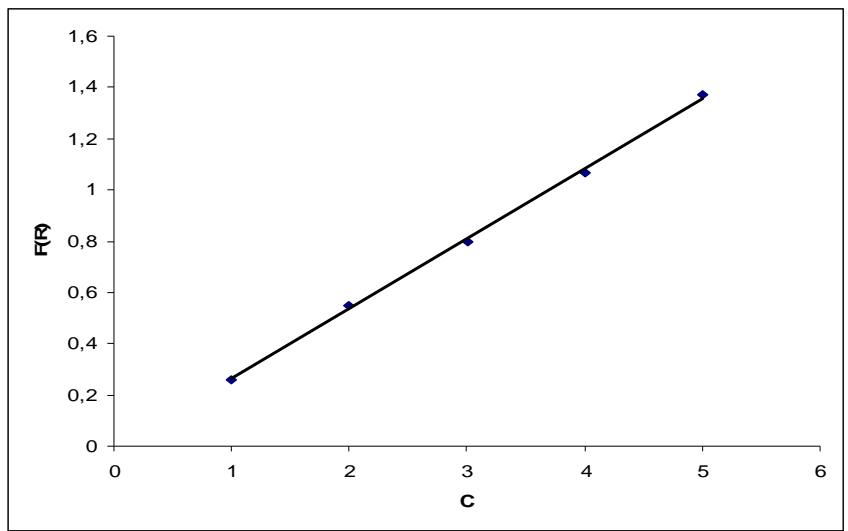

Figure 7: The Calibration Dependence Between the Optical Density and the Number of Mercury Ions

\section{CONCLUSION}

We came to the same conclusion by calculating the sensitivity of the Sendel reaction in $\mu \mathrm{g} / \mathrm{cm}^{2}$ per 0.001 light absorption (Table 2). Thus, in this work, the optimal conditions were selected for the development of a new method for spectrophotometric determination of mercury ions with improved metrological and analytical characteristics. 
In order to find out the determining possibility of mercury in real objects, model mixtures of various combinations, which mimic their composition, were simulated. The methodology and conditions of the sorption-spectroscopic methodology for determining mercury in the analyzed mixtures were the same as in the analysis of individual solutions.

Table 3: Spectrophotometric Determination of Mercury Ions in its Individual Solutions $(\mathrm{P}=0,95 ; \mathrm{n}=5)$

\begin{tabular}{|c|c|c|c|c|}
\hline $\begin{array}{l}\text { Introduced } \\
\text { mercury, } \\
\text { meg }\end{array}$ & $\begin{array}{c}\begin{array}{c}\text { Found } \\
\text { mercury, } \\
\text { mcg }\end{array} \\
\left(\bar{x}_{ \pm \Delta X)}\right.\end{array}$ & $\mathbf{n}$ & $\mathbf{S}$ & $\mathrm{Sr}$ \\
\hline 0,5 & $0,49 \pm 0,03$ & 5 & 0,06 & 0,123 \\
\hline 1,0 & $0,89 \pm 0,12$ & 4 & 0,09 & 0,112 \\
\hline 5,0 & $4,92 \pm 0,39$ & 5 & 0,32 & 0,066 \\
\hline 10,0 & $9,97 \pm 0,20$ & 5 & 0,17 & 0,017 \\
\hline 25,0 & $\begin{array}{r}25,01 \pm \\
0,1 \\
8\end{array}$ & 5 & 0,15 & 0,006 \\
\hline 50,0 & $\begin{array}{c}49,93 \pm \\
0,0 \\
6\end{array}$ & 4 & 0,04 & 0,001 \\
\hline
\end{tabular}

It is observed from the table that for all the determined amounts of mercury, sufficiently reproducible and correct results are obtained that are close to the corresponding concentrations introduced; in all cases, the determination errors do not go beyond the confidence interval, which indicates the absence of systematic errors.

Table 4: The results of the determination of mercury (II) ions in binary, ternary and more complex model mixtures $(\mathrm{P}=0,95$; $\mathrm{n}=5$ )

\begin{tabular}{|c|c|c|c|}
\hline $\begin{array}{c}\text { The composition } \\
\text { of the analyzed } \\
\text { mixture, mcg }\end{array}$ & $\begin{array}{c}\text { Found } \mathbf{H g}, \\
\mathbf{m c g}\left(\begin{array}{c}\bar{x} \\
\pm \mathbf{\Delta} \mathbf{X})\end{array}\right.\end{array}$ & $\mathbf{S}$ & $\mathbf{S r}$ \\
\hline $\mathrm{Hg}(1,0)+\mathrm{Pb}(2,0)$ & $1,02 \pm 0,22$ & 0,09 & 0,086 \\
\hline $\begin{array}{r}\mathrm{Hg}(2,0)+\mathrm{Fe}(50,0) \\
+\mathrm{Ni}(50,0)\end{array}$ & $1,96 \pm 0,18$ & 0,16 & 0,081 \\
\hline $\begin{array}{c}\mathrm{Hg}(3,0)+\mathrm{Cu}(20,0) \\
+\mathrm{Mn}(10,0)+\mathrm{Fe}(15 \\
, 0)\end{array}$ & $2,90 \pm 0,29$ & & 0,086 \\
\hline $\begin{array}{l}\mathrm{Hg}(1,0)+\mathrm{Ni}(30,0) \\
++\mathrm{Cu}(0,5)+\mathrm{Zn}(10 \\
, 0)+\mathrm{Cd}(5,0)\end{array}$ & $0,990 \pm 0,302$ & & 0,120 \\
\hline
\end{tabular}

It can be determined from the table, the sorption spectroscopic determination of mercury in complex model mixtures that simulate real objects is quite possible, and in all cases, the relative standard deviation does not exceed 0.120 , which indicates good accuracy and reproducibility of the developed sorption spectroscopic methods.

\section{REFERENCES}

1. Resolution of the Cabinet of Ministers No. 350 of October 19, (2016).

2. N.V. Lazereva, "Handbook for chemical engineers and doctors", Leningrad, (1968), pp. 256-260.

3. N.N. Roeva, S.B.Savvin, "Journal of analytic chemistry", (1992), pp. 1750-1763

4. R.F. Guryeva., S.B.Savvin, A.V.Mikhailova, Journal of analytic chemistry, (2003), pp. 302-383.

5. T.Tomoo, "Derivatives of thiopirazalone as analytical reagents. Extractionspestrophotometric determination of mercury(II) traus as triple complex compound of $\mathrm{Hg}$ (II) with thiopirine and eozine.", Bulletin of Chemistry and Pharmacy, (1988), pp.3139-3143.

6. A.L. Grigoryan, S.P.Lebedeva, R.G. Dayan, A.R. Grigoryan. "Acrychin reagent for extraction-photometric determination of microgram amounts of mercury (II)", Journal of Analytic chemistry, (1990), pp.896-899.

7. D.M. Zhilin, I.V. Perminova, B.C. Petrosyan, "Express method for the determination of mercury (P) in the presence of humic acids", Tomsk State University Journal, Moscow, (2001), pp.214-215.

8. S.A.Lygin, E. S.Purina. "Heavy metal ions in the soil of Birsk and the Birsk region", Universum: chemistry and biology: electron scientific journal, (2014).

9. G.V.Namsaraeva, "Analysis of soil pollution of agricultural land in the Irkutsk region",News electronic scientific journal, (2010). http://eizvestia.isea.ru

10. I.K.Huseynov,

N.Kh.Rustamov, "Extraction-photometric determination of mercury (P) byphenanthroline and dinitrobenzene with azopyrocatechol", Azarbaijan Chemistry Journal, (1985), pp.116-119.

11. V.P.Gladyshev, S.A. Levitskaya, L.M. Filippova, "Analytical chemistry of mercury", Science, Moscow, (1978), pp.67-70.

12. G.B.Slepchenko, N.P.Pikula, N.M.Dubova, T.I.Schukina, O.S.Zharkova, "Electrochemical water quality control (review)", Bulletin of the Tomsk Polytechnic University, (2009), pp.314.

13. N.Kh.Kutlimurotova, Kh.T.Dzhamolov, Z.A. Smanova, Kh.Sh.Yakhshieva, A.E.Yangiboev, "Spectrophotometric determination of mercury ions by the new reagent $\mathrm{N}$-methylanabazine- $\alpha$-azo-1,8-aminonaphthol -4,6-disulfonic acid", Young scientist, (2014), pp. 15.

14. Y.Y.Lurie, "Handbook of analytical chemistry", Chemistry, Moscow, (1979). 
15. K. Nakanishi, "IR - spectra and structure of organic compounds: translation from English", Mir, Moscow, (1965), pp. 140-144.

16. K. Nakamoto, "IR spectra of inorganic and coordination compounds", World, Moscow, (1996).

17. L.A.Kazitsyna, N.B.Kupletskaya, "The use of UV, IR and NMR spectroscopy in organic chemistr", Higher school, Moscow, (1971).

18. L.Bellamy, "New data on the IR spectra of complex molecules", Mir, Moscow, (1971), pp.318-325. 